\title{
Determination of Dynamic Deliverability Equation for Fractured Horizontal Well in Tight Gas Reservoir
}

Xiangji Dou*, Xinwei Liao, Xiaoliang Zhao, Huan Wang, Huawei Zhao and Dongfeng Zhao

Department of Petroleum Engineering, China university of Petroleum, Beijing, China

\begin{abstract}
The deliverability equation of gas well is important for productivity evaluation and performance forecasting. For fractured horizontal well in stress-sensitive tight gas reservoir, due to the pressure-dependencies of gas properties, reservoir/fracture permeability and high-velocity non-Darcy flow, the deliverability equation would not be constant but is also dynamic. Traditionally, the relationship between reservoir/fracture permeability is commonly be obtained by laboratory experiments, which is expensive and time-cost. Besides, the predecessor's studies which neglect the pressure-dependence of high velocity non-Darcy flow would also lead inaccuracy. Therefore, this paper presented a new method to quantify pressure-dependence of reservoir/fracture permeability as well as obtain dynamic deliverability equation for multi-fractured horizontal well in tight gas reservoir considering non-constant non-Darcy flow. This method is validated by an actual well in Sulige tight gas field in Ordos Basin, China. The result shows that this method is accurate and can contribute to the effective development of stress-sensitive tight gas reservoir.
\end{abstract}

Keywords: Tight gas reservoir; Fractured horizontal well; Deliverability equation; Non-darcy flow; Stress-sensitivity

\section{Nomenclature}

Field variables

$\mathrm{D}_{\text {res }}$ non-Darcy flow coefficient in reservoir, $\left(\mathrm{m}^{3} / \mathrm{d}\right)^{-1}$

$D_{f}$ non-Darcy flow coefficient in fracture, $\left(\mathrm{m}^{3} / \mathrm{d}\right)^{-1}$

$\mathrm{F}_{\mathrm{C}}$ fracture conductivity, $\mathrm{md} \bullet \mathrm{m}$

$\mathrm{F}_{\text {CDIM }}$ the ratio of $\mathrm{F}_{\mathrm{C}}\left(\mathrm{p}_{\mathrm{r}}\right)$ to $\mathrm{F}_{\mathrm{C}}\left(\mathrm{p}_{\mathrm{i}}\right)$

$\mathrm{q}_{\mathrm{g}}$ gas rate, $\mathrm{m}^{3} / \mathrm{d}$

$\mathrm{h}$ formation thickness, $\mathrm{mm}$

$\mathrm{k}$ formation permeability, md

$\mathrm{k}_{\mathrm{f}} \quad$ hydraulic fracture permeability, md

$\mathrm{P}$ pressure, $\mathrm{MPa}$

$\mathrm{P}_{\mathrm{i}} \quad$ initial pressure, $\mathrm{MPa}$

$\mathrm{P}_{\mathrm{r}} \quad$ average formation pressure, $\mathrm{MPa}$

$\mathrm{P}_{\mathrm{wf}}$ bottom hole flowing pressure

$\mathrm{x}_{\mathrm{f}} \quad$ fracture half-length, $\mathrm{m}$

$\omega$ fracture width, $\mathrm{m}$

\section{Introduction}

It is widely accepted that for some tight gas reservoirs, reservoir permeability are sensitive to pressure change. To investigate this pressure-dependence, a large amount of experiments were conducted. Gray et al, Brace, Jones and Owens [1-3] proved that an exponential relationship between permeability and pressure are found in several typical rocks.

$$
k / k_{i}=\exp \left(-\gamma\left(p_{i}-p\right)\right.
$$

Besides, with widely application of fractured well, the issue that how fracture parameters would change with pressure has attracted plenty of attention. Furthermore, for fractured horizontal well, high-velocity
non-Darcy is very important because of relatively high productivity. Due the existence of fracture, non-Darcy flow is influenced by fracture parameters as well as reservoir properties. The significance of nonDarcy flow has been emphasized in some papers. However, the stresssensitive non-Darcy flow coefficients in both reservoir and fracture still remain to be investigated. For field application, determining this relationship with core experiment is not economical, so an easier and accuracy method is needed to obtain the pressure-dependencies of these parameters. Deliverability equation is essential to determine productivity of gas well and thus forecast well performance. There are three formats of deliverability equations. They are characterized by pressure, square of pressure and pseudo-pressure, respectively. Among these, the equation characterized by pseudo-pressure (Eq. 4) is the most accurate but may lead to complexities while the one characterized by pressure (Eq. 2) may result in significant inaccuracy. In practice, deliverability equation characterized by square of pressure (Eq. 3) is common used in field case.

$$
\begin{aligned}
& p_{r}-p_{w f}=A q+B q^{2} \\
& p_{r}{ }^{2}-p_{w f}{ }^{2}=A q+B q^{2} \\
& \psi_{r}-\psi_{w f}=A q+B q^{2}
\end{aligned}
$$

Where A represents degree of percolation resistance force in reservoir and viscous force in fracture, $B$ represents degree of inertial resistance caused by turbulence flow. However, for tight gas reservoir, it is always very costly and money-consuming to conduct actual productivity well test to determine deliverability equation and open-

*Corresponding author: Xiangji Dou, Department of Petroleum Engineering China university of Petroleum, Beijing, China, Tel: +861089733256; E-mail: douxiangji@gmail.com.

Received September 24, 2014; Accepted February 28, 2015; Published March 07, 2015

Citation: Dou X, Liao X, Zhao X, Wang H, Zhao H, et al. (2015) Determination of Dynamic Deliverability Equation for Fractured Horizontal Well in Tight Gas Reservoir. J Pet Environ Biotechnol 6: 210. doi:10.4172/2157-7463.1000210

Copyright: () 2015 Dou X, et al. This is an open-access article distributed under the terms of the Creative Commons Attribution License, which permits unrestricted use, distribution, and reproduction in any medium, provided the original author and source are credited. 
hole capacity due to ultra-low permeability. Besides, the pressuredependencies of parameters mentioned above can lead the deliverability to be dynamic. It is also impractical to conduct productivity well test for several times during well life to obtain the dynamic deliverability equation for different production phase. Therefore, an effective and fast simulation method is required to obtain the dynamic deliverability equation and investigate the influence of pressure-dependent parameters on this equation. The objective of the paper is, therefore, to provide a new method to determine the pressure-dependencies of several parameters and obtain dynamic deliverability equations for fractured horizontal well in tight gas reservoir.

\section{Determination of Dynamic Deliverability Equation}

For a fractured horizontal well with several fractures, due to the complexities of reservoir and fractures, it is difficult to determine deliverability equation exactly with analytical method. On the other hand, field test methods are always costly and time-consuming, which cannot meet the demand of tight gas reservoir development. Modified isochronal well test simulation, a new method to determine deliverability is adopted in this paper to solve the problem. Core idea of this method is obtaining the pressure change corresponding to a reasonable simulated productivity well test system based on a numerical model, which is built based on production data analysis. Through establishing numerical model with the parameters of reservoir and well derived from production data, the bottom hole flowing pressure data of productivity well test for fractured horizontal well can be obtained by simulating the process of modified isochronal well test. The binomial deliverability equation and open-hole capacity of gas well could be determined with the rate and pressure obtained. The practical application shows that this method has advantages of strong pertinence, convenient operation, reliable result and time-saving. Different from conventional horizontal well, wellbore of fractured horizontal well in tight gas reservoir is always cased or contributes relatively litter gas compared to the fractures. Research shows that as a result of high velocity, additional drawdown due to turbulence flow within and around the fracture cannot be neglected. Thus, Darcy's flow, which describes velocity as a linear function of the pressure gradient and neglects inertial forces, is not suitable for fractured well in tight gas reservoir. The characteristics of fluid flow can be described with Forchheimer law [4].

$$
\frac{\partial p}{\partial x}=\frac{\mu}{k} \cdot v+\beta \cdot \rho \cdot v^{2}
$$

According to high-velocity non-Darcy flow theory, a factor $\mathrm{Dq}_{\mathrm{sc}}$ similar to skin factor can be used to describe the degree of high-velocity non-Darcy flow. Where, D is called non-Darcy flow coefficient. In this paper, non-Darcy flow in reservoir as well as in fractures is considered.

$$
\begin{gathered}
D_{r e s}=2.191 \times 10^{-18} \frac{\beta_{r e s} \gamma_{g} K_{r e s}(\bar{p})}{N^{2} \mu_{g}(\bar{p}) h x_{f}} \\
D_{f}=2.191 \times 10^{-18} \frac{\beta_{f} \gamma_{g} K_{r e s}(\bar{p})}{N^{2} \mu_{g}(\bar{p}) w^{2} r_{w}}
\end{gathered}
$$

Where, velocity coefficient $\beta$ in reservoir and fracture can be expressed as Eq. (8) and Eq. (9), respectively [3].

$$
\begin{aligned}
& \beta_{\text {res }}=4.1 \times 10^{11} / K_{r e s}^{1.5} \\
& \beta_{f}=1 \times 10^{11} / K_{f}^{1.1}
\end{aligned}
$$

It can been conclude from Eq. (6 9) that $\beta$ and $D$ are permeabilitydependent (including permeability of formation and fracture). For stress-sensitive reservoir and fractures, permeability of formation and fractures would change with pressure, which leads to the pressuredependent (stress-sensitive) non-Darcy flow coefficient. Contrary to the conventional method, approach in this paper facilitates the consideration of highly inertial flow and accounts also for permeability (pressure) dependency of non-Darcy flow coefficients. In this case, due to the complexity of porous flow model and stress-sensitivities, obtaining parameters and open-hole capacity with a unique analytical equation turn out to be difficult. Therefore, Infinitesimal method theory can be used in obtaining formation and fracture parameters and thus determining productivity equation. A production history is divided into several segments, each with minor change in reservoir and fracture parameters. So, parameters including formation permeability, fracture half-length, fracture conductivity and non-Darcy flow coefficients can be treated as parameters with fixed value for each stage. By doing this, not only parameters and open-hole capacity needed for each stage can be obtained, but also the change rule of parameters and deliverability equation is investigated. Thus, the binomial deliverability equation of fractured horizontal well could be expressed as follows.

$$
\begin{aligned}
& \text { First stage } \\
& P_{r 1}^{2}-P_{w f 1}^{2}=A_{1} q_{g 1}+B_{1} q_{g 1}^{2}
\end{aligned}
$$

Second stage

$$
P_{r 2}^{2}-P_{w f 2}^{2}=A_{2} q_{g 2}+B_{2} q_{g 2}^{2}
$$

Nth stage

$$
P_{r n}^{2}-P_{w f n}^{2}=A_{n} q_{g n}+B_{n} q_{g n}^{2}
$$

By this analogy, binomial deliverability equations for different stages could be obtained. With infinitesimal analysis method, influence of formation/fracture parameters and non-Darcy flow coefficient change caused by stress-sensitivity on gas well productivity is quantified.

To build models for different pressure, reservoir and fracture parameters as well as the pressure-dependence of them needed be determined. For tight gas reservoir, as a result of stress sensitivities, the formation permeability, fracture parameters (half-length and conductivity) and non-Darcy flow coefficients would change with formation pressure. Thus, the accuracy of history-match would be reduced when a unique set of parameters are used. Therefore, with reasonable time of division, segmented history match method can be used to obtain parameters of each stages and analysis the relationship between them and pressure. Before segmented history match, based on the production data, flow-regime should be identified. Then PDA methods including straight-line and type-curve method modified for stress-sensitive reservoir are used to provide an initial history-match input. Due to the parameters change caused by stress-sensitivity, dynamic parameters need to be adjusted to reach a perfect match. The following is a brief description of workflow.

(1) Compile production and associated flowing pressures, fluid properties, initial reservoir pressures, volumetric reservoir information (reservoir thickness, porosity), wellbore and completion/stimulation data together with the initial value of dynamic parameters obtained by straight-line and type-curve. Based on the information above, an initial numerical model is built for history-match.

(2) An over-all history-match for the whole production history data is conducted to determine an approximate range of parameters 
so that to provide reference for segmented history-match. A deviation between matched curve and actual curve is always obvious in this step. The deviation is caused by stress-sensitivity.

(3) Based on the over-all history-match, segmented history-match is conducted for each stage. For this step, a reasonable time division is very important to get an accurate result. It should be noted that, non-Darcy flow coefficients used for history-match should satisfy the relationship between this coefficients and reservoir/fracture parameters.

(4) If transient well test are conducted to the well, the value obtained from well-test analysis should be used to validate the results.

(5) After completing the history-match for every segment, dynamic parameters for each segment are determined; the pressuredependencies of them are also quantified.

(6) Based on the change rule, value of dynamic parameters for every pressure could be determined, which is essential to forecast the deliverability equation.

With accurate parameters of each stage obtained by segmented history-match method, deliverability equations of each stage can be determined by modified isochronal well test simulation. The following workflow is recommended:

(a) For a certain pressure, calculate $\mu$ and $\mathrm{Z}$ with Lee and Gonzalez method, Beggs and Brill method, respectively.

(b) Based on the pressure-dependence of formation and fracture parameters obtained with $(1) \sim(6)$, formation permeability and fracture parameters (half-length and conductivity) are determined; velocity coefficient and non-Darcy flow coefficient can also be calculated.

(c) Compile dynamic parameters obtained above together with static parameters, numerical simulation model of fractured horizontal well for the pressure can be built.

(d) Based on the model, deliverability and open-hole capacity for the pressure are determined with modified isochronal well test simulation.

(e) If actual productivity well test are conducted to the well, the value obtained should be used to validate the results.

Depending on studies above, pressure-dependence of formation/ fracture parameters are obtained, based on which, dynamic deliverability equation for different pressure could be forecasted.

\section{Example Application}

The application of this method is illustrated with a field example of Sulige gas reservoir in Ordos Basin. Su-A is a typical fractured horizontal well completed in tight gas reservoir, which is multi-fractured in 5 stages, the heal-to-toe perforated length of the well is $552 \mathrm{~m}$. Firstly, production data (rate and flowing pressure) and information provided by well logging, core experiment and other technologies are collected (Table 1). Production data analysis is conducted to provide initial value for history-match together with logging and core experiment results, based on which, a numerical simulation model is built as shown in Figure 1 .

Then, an over-all history-match for the whole production history data is conducted to determine an approximate range of parameters so that to provide reference for segmented history match. A deviation between matched curve and actual data is obvious in the result of

\begin{tabular}{|c|c|}
\hline Parameter & Value \\
\hline porosity & 0.096 \\
\hline Net thickness $(\mathrm{m})$ & 8.7 \\
\hline Rock compressibility $(1 / \mathrm{Pa})$ & $7.5 \cdot 10^{-10}$ \\
\hline Reservoir temperature $(\mathrm{K})$ & 376.15 \\
\hline
\end{tabular}

Table 1: Value of static parameter for SU-A.

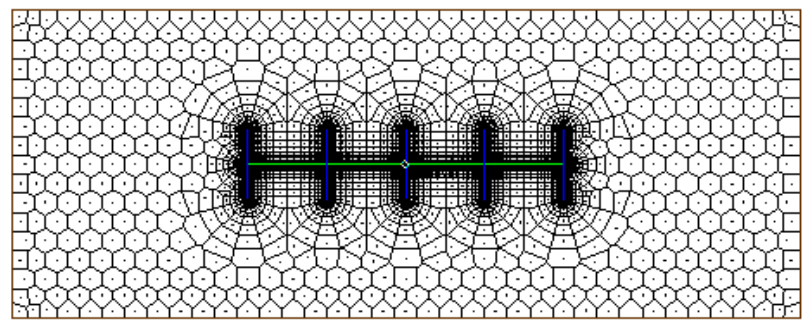

Figure 1: Gridding used in numerical simulation for SU-A.

\begin{tabular}{|c|c|c|c|c|}
\hline Segment & $\begin{array}{c}\text { Permeability } \\
\text { (md) }\end{array}$ & $\begin{array}{c}\text { Fracture half- } \\
\text { length }(\mathbf{m})\end{array}$ & $\begin{array}{c}\text { Fracture } \\
\text { conductivity } \\
\text { (md·m) }\end{array}$ & $\begin{array}{c}\text { Average } \\
\text { formation } \\
\text { pressure (MPa) }\end{array}$ \\
\hline 1 & 0.087 & 71 & 63 & 29.04 \\
\hline 2 & 0.081 & 63 & 48 & 26.5 \\
\hline 3 & 0.075 & 56 & 39 & 23.95 \\
\hline 4 & 0.071 & 51 & 33 & 21.41 \\
\hline 5 & 0.065 & 46 & 27 & 18.86 \\
\hline \multicolumn{5}{r}{ Table 2: Dynamic parameters obtained by segmented history-match. } \\
\hline
\end{tabular}

over-all history match a unique set of parameters, which is caused by significant stress-sensitivities in reservoir and fractures. Based on the over-all history match, segmented history-match is conducted for each stage. The parameters determined by segmented history-match method are shown in Table 2.

Based on the pressure-dependence of formation/fracture parameters, the relationships between stress-sensitive parameters and average formation pressure are investigated. The results show that exponential form could be used to describe the change of formation permeability and fracture parameters. Furthermore, the fracture conductivity drops faster than formation permeability when average formation pressure declines. However, in this case, non-Darcy flow coefficients in both fracture and formation increase, which caused additional drawdown and lead to negative effect on well production performance. Based on the relationship, the value of each parameter for certain pressure could be forecasted (Figures 2 and 3 ) and applied for deliverability equation determination.

With modified isochronal well test simulation, binomial deliverability equation coefficients and open-hole capacity of each stage are determined (Table 3).

At the first segment of well life, an actual productivity well test was conducted to SU-A, the equation obtained by the test analysis was $\mathrm{P}_{r}^{2}$ $\mathrm{P}_{\mathrm{wf}}{ }^{2}=23.58 \mathrm{q}_{\mathrm{g}}+0.176 \mathrm{q}_{\mathrm{g}}{ }^{2}$, While another test conducted during the fifth segment shows the equation was $\mathrm{P}_{\mathrm{r}}{ }^{2}-\mathrm{P}_{\mathrm{wf}}{ }^{2}=21.35 \mathrm{q}_{\mathrm{g}}+0.256 \mathrm{q}_{\mathrm{g}}^{2}$, Both of these are similar to the results obtained with the method proposed in this paper. Therefore, modified isochronal well test simulation method is a useful and economical method to determine productivity of fractured horizontal well in tight gas reservoir.

With this method, we forecasted deliverability for different pressure for Su-A, the results is shown in Figure 4. It can be concluded that with 
Citation: Dou X, Liao X, Zhao X, Wang H, Zhao H, et al. (2015) Determination of Dynamic Deliverability Equation for Fractured Horizontal Well in Tight Gas Reservoir. J Pet Environ Biotechnol 6: 210. doi:10.4172/2157-7463.1000210

Page 4 of 4

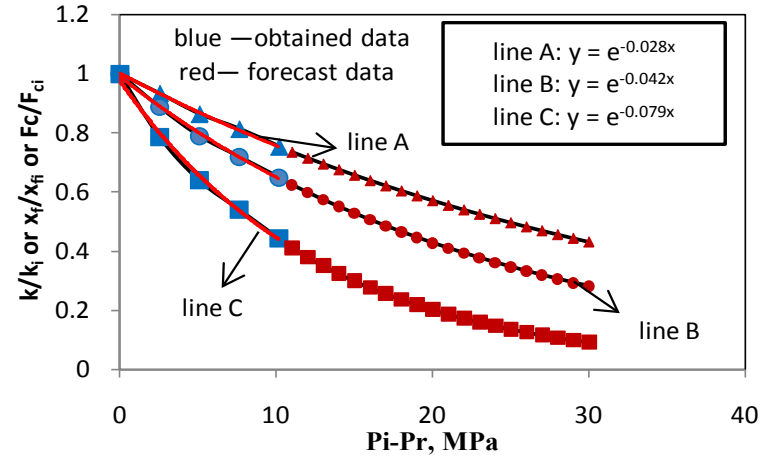

Figure 2: Relationship between dimensionless parameters and pressure: line $A / B / C$ refers to relationship between permeability/fracture half-length/ fracture conductivity and pressure, respectively.

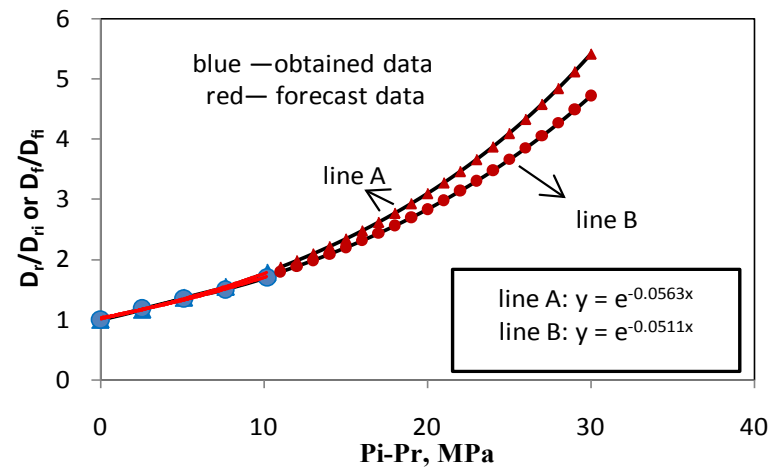

Figure 3: Relationship between dimensionless non-Darcy flow coefficient and pressure: line $A / B$ refers to therelationship between non-Darcy flow coefficient in reservoir and fracture and pressure, respectively.

\begin{tabular}{|c|c|c|c|}
\hline Segment & $\begin{array}{c}\mathbf{A} \\
\mathbf{M P a}^{2} /\left(\mathbf{1 0 ^ { 4 }} \mathbf{m}^{\mathbf{3}} / \mathbf{d}\right)\end{array}$ & $\begin{array}{c}\mathbf{B} \\
\mathbf{M P a}^{2} /\left(\mathbf{1 0}^{4} \mathbf{m}^{3} / \mathbf{d}\right)^{\mathbf{2}}\end{array}$ & $\begin{array}{c}\mathbf{q A O F} \\
\mathbf{1 0}^{4} \mathbf{m}^{3} \mathbf{d}\end{array}$ \\
\hline 1 & 23.9 & 0.182 & 28.9 \\
\hline 2 & 23.16 & 0.196 & 25.01 \\
\hline 3 & 22.37 & 0.213 & 21.31 \\
\hline 4 & 21.83 & 0.229 & 17.7 \\
\hline 5 & 21.3 & 0.251 & 14.29 \\
\hline
\end{tabular}

Table 3: Deliverability equation coefficients and open-hole capacity for each segment.

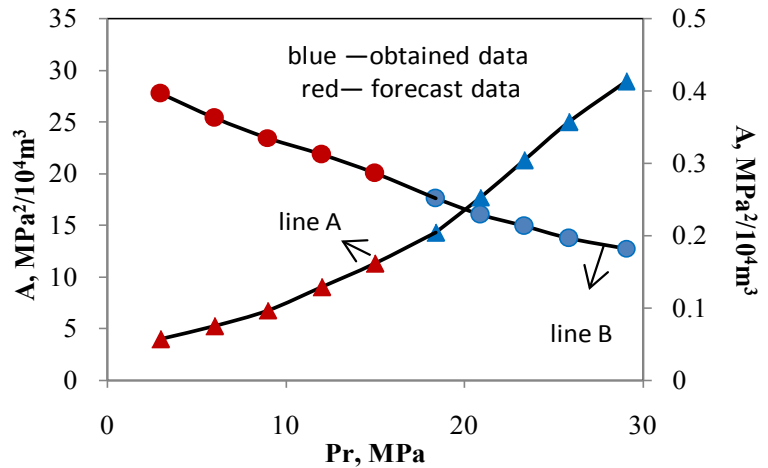

Figure 4: Relationship between coefficient $A / B$ and pressure: line $A / B$ refers to coefficient $A / B$, respectively. the decrease of average formation pressure, the value of coefficient a keeps decreasing, while the value of coefficient B shows an opposite character.

\section{Conclusions}

Based on the results of the present study, the following conclusions are studied.

- Segment history-match method can be used to determine change rule of dynamic parameters. With this method, stress-sensitive non-Darcy flow coefficients in both reservoir and fracture could be researched.

- Modified isochronal well test simulation presented in this paper is a useful and economical way to determine deliverability equation and open-hole, validated by actual productivity well test, the result obtained by modified isochronal well test simulation is accurate.

- Due to the existence of pressure-dependent gas properties and stress sensitivity, deliverability equation would not be constant during the well life. While stress-sensitive non-Darcy flow coefficients are taken into consideration, the change rule of deliverability equation would be much more complex.

\section{Acknowledgement}

This work was supported by the National Basic Research Program of China (973 program, grant No.2011CB707302), Chinese National Major Science and Technology Projects (2011ZX05016-006 and 2011ZX05009-004-001), The Specialized Research Fund for the Doctoral Program of Higher Education of China (No 20120007120007).

\section{References}

1. Gray DH, Fatt I (1963) The effect of stress on permeability of sandstone cores Society of Petroleum Engineers Journal 3: 95-100.

2. Brace WF (1978) A note on permeability changes in geologic material due to stress. Pure and applied geophysics 116: 627-633.

3. Jones FO, Owens WW (1980) A laboratory study of low-permeability gas sands. Journal of Petroleum Technology 32: 1631-1640.

4. Forchheimer P (1901) Wasserbewegung durch boden. Z. Ver Deutsch. Ing 45 1782-1788. 